\title{
A CLINICAL STUDY OF THE EFFECTS OF SHORT PERIODS OF SEVERE ANOXIA WITH SPECIAL REFERENCE TO THE MECHANISM OF ACTION OF CARDIAZOL "SHOCK"
}

\author{
BY
}

\author{
RUSSELL FRASER AND FRANCIS REITMANN \\ From the Unit, Maudsley Hospital, London
}

(ReCEIVEd 20Th FebruARY, 1939)

THERE has been some comment recently on the resemblance between the phenomena of anoxia and those observed in patients during insulin and cardiazol treatments. Some observers have gone so far as to suggest that the main pathogenetic mechanism for the clinical effects of these treatments is an induced cerebral anoxia. The work reported here was an attempt to test this hypothesis in relation to cardiazol " shock."

Subsequent to the completion of this work, Gellhorn (1938) has published a paper reporting animal experiments which show similarities between the effects of hypoglycæmia and anoxia, and also that oxygen deprivation potentiates the effects of hypoglycæmia and vice versa. In addition, he discusses at some length the evidence for considering anoxia as the pathogenetic factor in insulin and cardiazol phenomena. He is inclined to conclude that anoxia is a central factor, but adds that these treatments also produce considerable sympathetic (apparently central) stimulation in excess of that produced by anoxia ; this may be a significant difference as he points out. It is also relevant here to mention studies that Himwich (1937) and Dameshek (1935) have made of the cerebral metabolism during hypoglycæmia and the cardiazol fit, based on estimations of femoral arterial and jugular venous samples of blood. The results demonstrated that during severe hypoglycæmia there occurs a fall of oxygen consumption proportional to, but slightly less than the fall in glucose utilization. During the cardiazol fits a fall of arterial oxygen content to values varying between 50 per cent. and 70 per cent. of the oxygen capacity was observed towards the end of the seizure ; insufficient data were obtained to determine the cerebral oxygen consumption. The existence of this anoxia during the cardiazol fit is, of course, apparent to the observer, and to be expected after the combination of spasm and apnœa that occurs. But histological findings (Stief, 1937 ; Reitmann, 1938) suggest the occurrence of vascular spasm in the brain during hypoglycæmic and cardiazol convulsions and this 
may lead to a more severe cellular anoxia. The abolition of these convulsions when Amyl Nitrite (Reitmann, 1938) is administered simultaneously with cardiazol indicates that vasoconstruction may be a factor in producing the fit.

But whether the anoxia in the cardiazol fit is merely a secondary effect of the fit might be determined by comparing the results of inducing comparable anoxia by other methods, preferably such as would produce practically no other coincidental effect. For this, the administration by a mask of a controlled reduced percentage of oxygen seemed most suitable and was the procedure that we carried out on four schizophrenic patients (44 administrations) together with noting the immediate and late effects. Armstrong (1938) reports some similar experiments giving short periods of severe anoxia to animals, but there appears to be little available reference among the extensive work on this subject to the clinical effects in men of uncomplicated severe anoxia (under 8 per cent. oxygen). In most of the clinical reports of severe anoxia in man, the pathogenesis has been complicated by other factors-such as carbon monoxide poisoning or strangulation with its vascular concomitants. Therefore, as both the rapidity of onset and the duration of induced unconsciousness were similar to those seen with cardiazol therapy, it seemed desirable to put on record the clinical abnormalities observed during this anoxia.

\section{Method}

An apparatus designed for giving gas and oxygen anæsthesia at atmospheric pressure was used with the usual face mask and a cylinder of pure nitrogen in place of nitrous oxide. After a preliminary trial with different percentages of oxygen for varying periods of time, we finally adopted the following procedure.

It was best to give a preliminary period of two minutes anoxia of lesser severity which induced some dimming of consciousness without the unpleasant dyspnœa caused when the final percentage was given from the start. The procedure ultimately adopted was : (a) 3.5 per cent. oxygen for the first 2 minutes ; (b) 2 per cent. oxygen for 3 to 4 minutes ; within $1 \frac{1}{2}$ to 2 minutes' unconsciousness occurred, and was allowed to persist for $1 \frac{1}{2}$ to 2 minutes in the absence of complications ; (c) termination : 100 per cent. oxygen was then turned on till evidence of fairly complete return of consciousness, which should not take longer than 30 seconds.

Messrs. Coxeter and Son, Ltd., of the Morden Factory Estate, Morden Rd., S.W.19, kindly analysed the gases delivered by the apparatus under normal and heavy breathing with the following results :

\begin{tabular}{c|c|c}
\hline $\begin{array}{c}\text { PRESUMED PERCENTAGE OF } \\
\text { OXYGEN (FROM DIAL } \\
\text { READINGS) }\end{array}$ & \multicolumn{2}{|c}{ ACTUAL PERCENTAGE OF OXYGEN } \\
\cline { 2 - 3 } & WITH NORMAL BREATHING & WITH HEAVY BREATHING \\
\hline 2.0 & 2.0 & 1.6 \\
3.5 & 3.7 & 3.0 \\
6.0 & 6.8 & 5.0 \\
\hline
\end{tabular}

A small degree of rebreathing was allowed (because of the rapid change to very deep breathing), so that in all administrations there was probably some rise in the 
percentage of alveolar $\mathrm{CO}^{2}$, but the extent of this was not measured. During the administration, observations were made of the onset and termination of unconsciousness, any neurological abnormalities, and also the pulse, respiration, and blood pressure were recorded at half-minute intervals. The patients were usually asked to count when the mask was applied; cessation of counting was taken to indicate loss of consciousness.

It is relevant to mention that the procedure required a close supervision of these signs, especially of the character of the breathing; any significant weakening or irregularity was taken as absolute and immediate indication for cessation of the anoxia. For the first treatment only a short period of unconsciousness was allowed, which was gradually prolonged on subsequent days provided the time taken to awake did not exceed 45 seconds, and no other complications occurred. This treatment was given to fasting patients between eight and nine in the morning on two or three days of the week ; after eleven in the morning they were allowed the normal daily routine of the ward.

After the completion of the series of anoxia treatments the patients were given a course of cardiazol injections : this, unfortunately, did not produce a significant improvement, except perhaps with Case "W," whose treatment is not yet completed, and so possible therapeutic benefits cannot be discussed.

\section{Results}

\section{Clinical Picture during Anoxia}

As has been the experience of other workers, this varied in the lesser details among different patients, though it was fairly consistent for each patient from day to day. During the preliminary period of 3.5 per cent. oxygen and during the first 2 minutes of 2 per cent. oxygen there were merely slight cardiovascular and respiratory changes. The abnormalities observed after the loss of consciousness which then occurred may be described in two stages :

Initial Stage of Unconsciousness.-This stage was generally associated with spontaneous movements, and was usually reached $1 \frac{1}{2}$ minutes after commencing to breathe 2 per cent. oxygen. The onset was delayed a further $1 \frac{1}{2}$ minutes or more in some patients who developed little hyperpnœa ; these patients always had few, if any, associated spontaneous movements. During this stage the pulse-rate rose rapidly to about 140 per minute, the respirations deepened and increased to 35-40 per minute, while the systolic blood pressure rose $20 \mathrm{~min} . \mathrm{Hg}$. together with a slight rise of diastolic blood pressure. Early in this period there appeared various types of spontaneous movements :

(i) Vague restlessness with poorly co-ordinated movements in the limbs ; with one patient rhythmic " bicycling" movements of the legs always occurred at this phase ; with others there was general motor unrest, often suggesting apprehensiveness, although, after the first few days, most of the patients were not apprehensive before the treatment.

(ii) Typical myoclonic twitchings were also seen in most patients at this stage-in the face and arms mostly - but never very severe or extensive. Sudden twitching movements of whole limbs were seen occasionally.

The only abnormal physical sign on examination of the nervous system at this stage was a general increased excitability of tendon jerks.

Stage of Extensor Hypertonus.-After about one minute of the former stage 
signs of hypertonus gradually appeared, and after a transitional period lasting about one minute this stage was fully developed with intense muscular hypertonus dominating the clinical picture. Hypertonus appeared first in the neck and chest, where it was perhaps exaggerated by the strenuous respirations; at first it was fluctuating and not purely extensor. Short spasms into extension and pronation were next seen at intervals in the arms-similar to the extensor spasms seen in the deeper stages of hypoglycæmic coma, and during the recovery from cardiazol fits. At the same time transient torsion spasms in flexion or extension appeared which involved the whole of one side of the body and included conjugate deviation of the eyes to the same side. Finally persistent bilateral generalized and very marked hypertonus developed, appearing first in the body and legs, where it was always extensor in distribution. The position of the arms varied : at first the limb tended to fix in whatever position it was held artificially, reminiscent of tetany. Apart from such interference, the arms generally adopted first the flexed posture adducted across the body in semi-pronation, with the hands clenched or sometimes in the typical tetanic posture. If the anoxia was further prolonged the arms tended to move into the position of extension, at first nearly parallel with the body axis, but later coming forward to a varying angle in front of it in a position of pronation. The contraction was so strong that it was almost impossible to alter any of these postures and it was impossible to elicit any reflex response. Towards the end of this stage, bouts of generalized fine tremor resembling shivering were occasionally seen; in one patient an erection occurred at this stage. It was found that $\frac{1}{2}$ a minute was the maximum safe duration for this persistent hypertonus.

During this stage the blood pressure, both systolic and diastolic, rose steadily, reaching their maximum with the onset of persistent hypertonus, but pulse rate or respiration rate changed little from the values of the previous stage.

Waking Period.-At first the anoxia was terminated by removing the mask and allowing the patient to breathe air. Under these conditions, it was found that the patient lost all neurological abnormalities and could reply to questions within $\frac{1}{2}$ to 1 minute if the anoxia had not been unduly prolonged; for a further 5 minutes, the patient felt listless, drowsy, with a slight headache, giddiness, and occasionally some deafness or tinnitus. Some of the patients also mentioned having some black or coloured spots in front of the eyes, or a feeling of blood rushing through the head before complete recovery. When the patient was given 100 per cent. oxygen, speech returned within 15 to 30 seconds, and the subsequent drowsy listless phase lasted about 2 to 3 minutes. The blood pressure quickly subsided to normal levels, generally within 2 to 3 minutes, and the pulse-rate was normal after 5 minutes.

The severity of the anoxia was well reflected in the time of awakening; and prolongation or any unusual symptoms during this waking phase indicated a severe exposure. This was best illustrated by the occasion on which the most severe anoxic effects were observed. One day, with patient " $\mathrm{T}$," unconsciousness occurred $\frac{1}{2}$ minute after he had been given 2 per cent. oxygen (instead of $1 \frac{1}{2}$ minutes, which was usual for this patient) ; stage 2 had com- 
menced after a further $\frac{1}{2}$ minute, and was allowed to last for $1 \frac{1}{2}$ minutes. At this point, the blood pressure was $210 / 130$, pulse-rate was 150 , and respirationrate was 36, with generalized extensor hypertonus; the respirations, which had been deep and regular throughout, became suddenly irregular and more shallow, whereupon 100 per cent. oxygen was administered at once together with some $\mathrm{CO}_{2}$. Apnœa then occurred for $\frac{1}{2}$ a minute, after which deep, gasping respirations began and, in a few seconds, vague, restless, motor excitement. Within a minute of giving the oxygen the patient was turning, writhing, and struggling; he was confusedly aware of stimuli, not recognizing the doctors, and calling out : "Where am I ?" After 2 minutes of this delirious confusion, he lay back, adequately orientated, and spoke of having had a dream and not being able to understand where he was ; he was then giddy, though not feeling the room going round in any systematic direction, complained of seeing bright lights, and of feeling dazed and drowsy with a headache. At the termination of his excitement, his pulse was 112 , respiration rate was 24 , and blood pressure was $190 / 80$; 2 minutes later his pulse-rate was 100 , respiration-rate was 24 , and blood pressure was 140/80. After 20 minutes he felt normal, apart from a headache and general tiredness, which persisted till evening.

When asked later to describe the feelings during the induction of anoxia, the patients generally mentioned only an unpleasant dyspnœa. Often, although they had been indubitably unconscious, they insisted that they had not gone to sleep ; on being questioned they could not remember some incidents such as when plantar responses were elicited ; at other times they mentioned a feeling of slight suffocation, after which they went to sleep. There was never any evidence of retrograde amnesia-and they could report orders given them just prior to unconsciousness. On one or two occasions the patient was slightly but definitely euphoric and more talkative than usual during the recovery period. But on most occasions no significant psychological changes were noted during this period.

\section{Cardiovascular and Respiratory Changes}

These are summarized in Table 1 , showing the average values of $\frac{1}{2}$-minute intervals after commencing the 2 per cent. mixture ; the range in individual readings was not so different from the averages as to make it worth complicating the table by giving the extremes from which these were computed.

These correspond to the results obtained with animals (Armstrong, 1938 ; Haldane and Priestley, 1935). It will be noted that in the early phases there is a rise of both pulse and respiration rate. The respiration reaches a rate of 35-40 within the first minute, after which the depth continues to increase till about a $\frac{1}{2}$ to 1 minute after the loss of consciousness ; thereafter both rate and depth usually remain constant. $\mathrm{CO}_{2}$ accumulation occurring within the apparatus is doubtless responsible for some of the respiratory stimulation. The pulse rate reaches about 140 approximately coincident with the onset of unconsciousness, and thereafter remains constant. The blood pressure rises steadily throughout and more rapidly after the onset of unconsciousness. In view of 


\begin{tabular}{|c|c|c|c|c|c|c|}
\hline 30 & & $S S E L L$ & $4 S E R A$ & $D F R A N$ & (10.7) & \\
\hline 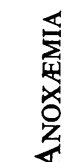 & $m$ & 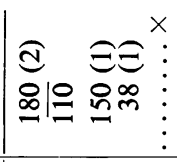 & 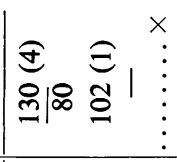 & 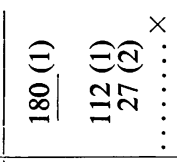 & 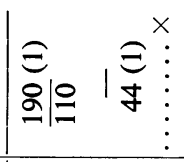 & 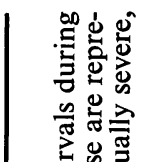 \\
\hline $\begin{array}{l}\text { o } \\
z \\
0\end{array}$ & $m$ & 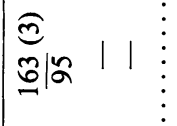 & 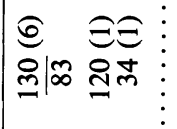 & 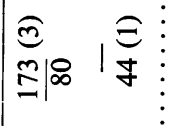 & 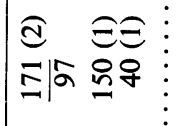 & 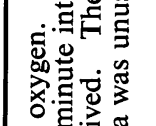 \\
\hline 曷 & $\star$ & 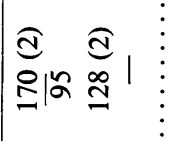 & 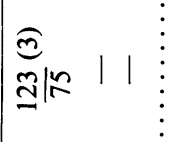 & 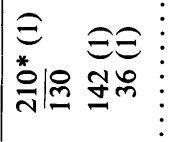 & 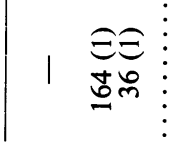 & 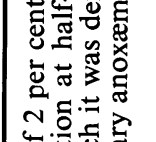 \\
\hline 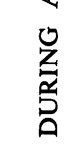 & $N$ & 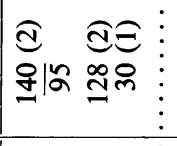 & 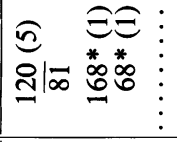 & 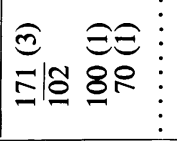 & 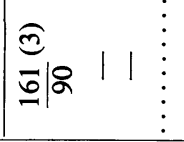 & $\bar{x}_{00}$ \\
\hline 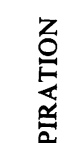 & $\nexists 2$ & 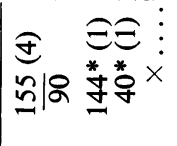 & $\underbrace{\infty}_{\varrho}|\infty|$ & 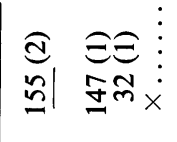 & 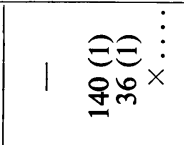 & $\begin{array}{l}0.0 \\
0 \\
0\end{array}$ \\
\hline 会 & - & $\begin{array}{ll}\Xi & \Xi \Xi \\
\approx 18 & 0\end{array}$ & 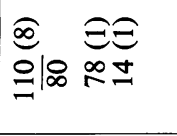 & 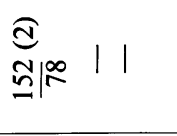 & 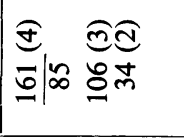 & $\begin{array}{l}x \\
0 \\
0 \\
\vdots\end{array}$ \\
\hline 氙 & $\pi N$ & 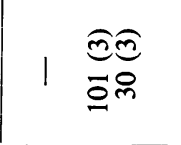 & 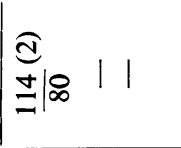 & 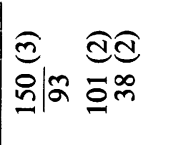 & 111 & \\
\hline 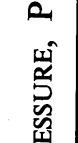 & 0 & $\begin{array}{ll}E & \hat{\sigma} \sigma \\
\dot{m} \mid \sigma & \infty ర 0\end{array}$ & 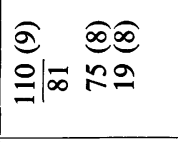 & 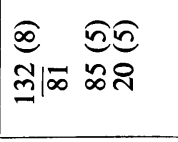 & 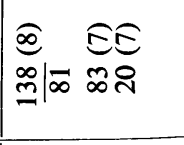 & \\
\hline 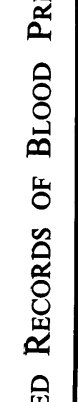 & 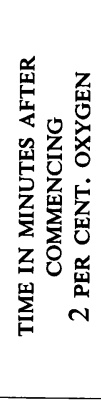 & 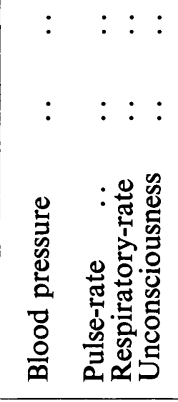 & 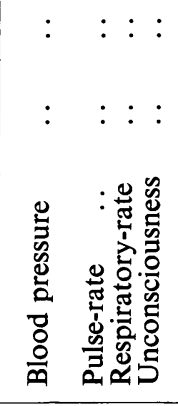 & 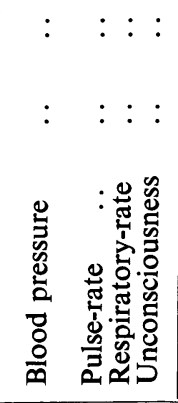 & 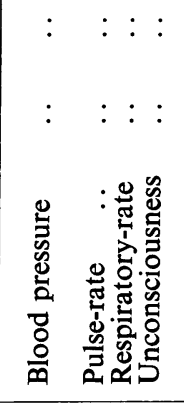 & 焉 \\
\hline$\sum_{\substack{5 \\
\vdots}}^{\infty}$ & & 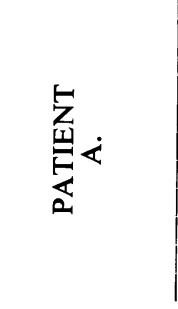 & 空 & 点 & 突山 & 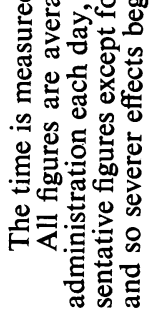 \\
\hline
\end{tabular}


these changes in pulse-rate and blood pressure there was presumably considerable increase in circulation rate during the anoxia. It will be noted that these responses, except for the pulse-rate, were minimal for patient " W," who was asthenic, took the treatment very apathetically, and breathed shallowly throughout. The shallow breathing certainly would delay the production of the anoxia, but there also seemed to be significantly less reaction to its effects. On all occasions, the subsidence of these cardio-respiratory changes at the end of the anoxia period was rapid, generally being completed within 2 to 3 minutes, though the pulse-rate remained somewhat elevated for a further 2 to 3 minutes.

\section{Variations in the Clinical Effects}

With the same patient the effects were, in general, consistent from day to day, when the same dosage was given. There was an impression that some adaptation did occur over the course of the treatment, but the rapid development of the anoxia made reliable measurement of such slight differences in its effects as might have occurred too difficult. At the commencement, different percentages were tried before adopting the routine mentioned above. For example, giving 6 per cent. oxygen it was found that at the end of 6 minutes there was some rise of blood pressure to $160 / 70$, but no loss of consciousness, though this then occurred after $\frac{3}{4}$ minute of 2 per cent. oxygen. On a few occasions, where first 2 minutes of 2 per cent. oxygen, and then 2 minutes of 6 per cent. was given before the final 2 per cent., the patient re-awakened partially during the period of 6 per cent. ; and after this preliminary preparation, the stages in the final 2 per cent. period were all about a $\frac{1}{2}$ minute earlier.

Concerning the variations in individual patients, it might be mentioned that patient "A" was a pyknic, well-built individual, and showed a more asthenic vascular response and more spontaneous twitchings. This might be compared with patient "W," who was asthenic and of rather poor physique, and who showed the opposite in these respects-even showing no rise of blood pressure or spontaneous movements or twitchings, despite unconsciousness for 1 to 2 minutes in some treatments. Individual differences were no longer apparent in the clinical picture of the full developed stage 2 . The time interval to the onset of unconsciousness was not very different among our patients, except for patient " W," who, probably due to his shallow breathing, was always much slower in becoming unconscious (always 2 minutes and sometimes $2 \frac{1}{2}$ to 3 minutes after commencing 2 per cent. oxygen).

\section{Prolonged and Persistent Effects}

No permanent psychological or psychiatric changes were noted in any of the four patients during or after the treatment. Dr. Blackburn, psychologist to the hospital, kindly gave the Babcock deterioration test to the patients at the end of the treatment, having also previously given a comparable test to two of the patients. These tests showed no evidence of deterioration in any mental functions. 
Complete blood counts taken before and after the completion of the treatment showed no differences. One sample, taken 2 hours after treatment, showed a rise of $1,000,000$ red cells and of 5 per cent. hæmoglobin which had subsided the next day.

\section{Discussion}

From the small number of cases treated it is, of course, not possible to conclude that the therapeutic effects of cardiazol treatment cannot be reproduced by giving comparable periods of severe anoxia. Nevertheless, it is of interest to compare the clinical picture of severe anoxia with the phenomena of the cardiazol fits, in order to try to assess the role that anoxia may play in the pathogenesis of the cardiazol fit and its associated phenomena.

In this respect the most significant feature is the complete absence of epileptiform fits from the clinical effects of rapid severe anoxia. Unconsciousness of about 2 minutes' duration was produced in our patients; yet it is doubtful whether unconsciousness is ever produced by cardiazol without a fit. But, with our patients, after spontaneous movements and twitchings which were fewer and less vigorous than those seen preceding a cardiazol fit, there developed instead a state of persistent strong hypertonus associated with deep coma. If this stage were prolonged, respiratory paralysis was apt to occur, though not epileptiform fits. This sequence was also observed by Armstrong (1938) during experiments in which he gave comparable short severe anoxia to animals, and found that prolongation resulted in death by respiratory paralysis, but not fits. Epileptiform fits have been seen as a late phenomenon during the recovery phases after severe prolonged anoxia ; but apparently anoxia cannot induce fits with the rapidity of cardiazol. This is also in accord with the conclusion of Simpson and Barker (1938) that anoxia does not play a role in precipitating the epileptic fit. They subjected 13 epileptic patients to anoxia (between 14 per cent. and 9 per cent. oxygen) for 36 hours without producing fits. There was also a slight difference in the vascular responses. Though the changes during the anoxia were similar to those during the cardiazol fit, the pulse-rate and blood pressure returned to normal more rapidly after the termination of the anoxia than during recovery from the cardiazol fit, and no irregularities of the pulse were seen.

Comparison of the neurological effects of anoxia with those seen before and after the cardiazol fit or following subconvulsive doses of cardiazol does not, however, lead to any definite conclusions. While we were unable to determine whether the motor pattern of the spontaneous movements of anoxia has features in common with that of cardiazol, there would appear to be some differencesin their severity, and in the absence of some typical cardiazol movements from anoxia. Spontaneous movements and myoclonic twitchings during anoxia were less frequent and less vigorous than the corresponding movements seen before the cardiazol fit. Although with patient "A " we were unable to reproduce the bicycling movements with cardiazol, this was possibly due to the difficulty we experienced in selecting a suitable subconvulsive dose. Such bicycling movements have been seen at times before or after a cardiazol fit. But the 
initial fluttering of the eyelids, the cough, and the sudden opening of the jaw typically seen before a cardiazol fit were never seen in these patients during anoxia. Further tonus disturbances similar to those during anoxia have not been seen with subconvulsive doses of cardiazol. They may be seen during the recovery from the cardiazol fit, as well as during the fit. But, in these circumstances, their causation must be ascribed at least partly to the fit itself.

Such similarities as we observed indicate that at least the later stages of nervous system disintegration under defect of oxygen are comparable to those induced by the cardiazol fit or insulin. In this respect, an interesting additional observation may be made concerning the prolonged waking period seen in some patients after excessive anoxia. This was reminiscent of the somewhat rare clinical picture of the insulin coma unreversed after the giving of intravenous sugar (" irreversible" coma) or of the delayed recovery after severe cardiazol fits. Such patients all show restless confusion with vague generalization, motor excitement, a tendency to opisthotonus and writhing, deep gasping respirations, and a rapid pulse. This may signify that the after-effects in the nervous system are similar, whether they follow excessive anoxia, cardiazol, or insulin coma. Recent histological work (Meyer, 1936) points to the selective action of anoxia on different parts of the brain ; this would lend weight to the hypothesis that all these after-effects depend on some common factor, which might well be anoxia.

The clinical comparison, however, has suggested the conclusion that cardiazol produces some other important changes that cannot be produced by severe anoxia of similar duration-evidenced most especially in the production of an epileptiform fit. Therefore, although the anoxia may play a part in the pathogenesis of cardiazol effects, it presumably cannot be regarded as the most important mechanism of its action. Even were the effects of anoxia and cardiazol similar, it would not follow, of course, that anoxia is the pathogenetic basis of its action.

\section{Summary}

1. A report is made of the clinical picture observed during short periods of severe anoxia administered to four schizophrenic patients on 44 occasions in all. Anoxia was produced by means of a mask from a gas anæsthetic apparatus which was adjusted to deliver 3.5 per cent. oxygen in nitrogen for 2 minutes followed by 2 per cent. oxygen for about 3 minutes.

2. The clinical effects are reported. A rise of pulse-rate, respiration-rate, and blood pressure, occurred continuously throughout and subsided rapidly after cessation. The neurological disturbances are described in two stages. One and a half minutes after the beginning of the 2 per cent. oxygen administration there was loss of consciousness with, in some seconds, myoclonic twitchings and various ill-defined spontaneous movements. After a further $\frac{1}{2}$ minute there followed a transitional phase of slight tonus abnormalities, which culminated after a further minute in the fully developed second stage or phase of tonic extensor hypertonus. If the mask was removed within $\frac{1}{2}$ a minute of the onset 
of this stage, the patient woke within 30 seconds, after which mild after-effects lasted a further 5 minutes.

3. The clinical state of short, severe anoxia was considered to differ significantly from the effects of convulsive doses of cardiazol, particularly in respect of the absence of epileptic fits. The spontaneous movements were less frequent and vigorous, and the vascular effects subsided more rapidly.

4. No clinical benefit was observed in these cases.

5. The recovery phase observed after one excessive dose of anoxia was strongly reminiscent of the rare delayed recovery from severe cardiazol fits or "irreversible" insulin coma.

In conclusion we wish to thank Professor Mapother for permission to publish these observations. We also wish to acknowledge our indebtedness to Messrs. A. Charles King, Ltd., 34 Devonshire St., W.1, for their courtesy in lending an anæsthetic apparatus for these experiments.

\section{REFERENCES}

Armstrong, H. G., and Heim, J. W. (1938). Journ. of Aviation, 9, 45.

Dameshek, W., and Meyerson, A. (1935). Arch. Neurol. Psychiat., 33, 1.

Gellhorn, E. (1938). Arch. Neurol. Psychiat., 40, 125.

Gibbs, F. A., Gibbs, E. I., and Lennox, W. G. (1935). Amer. J. Physiol., 111, 557.

Haldane, J. S., and Priestley, J. G. (1935). Respiration. London, Oxford.

Himwich, H. E., and Fazekas, J. F. (1937). Endocrinology, 21, 800.

Himwich, H. E., Bowman, K. M., Fazekas, J. F., and Orenstein, L. L. (1937). Proc. Soc. exp. Biol. Med., 37, 359.

Meyer, A. (1937). Proc. Roy. Soc. Med., 29, 1,175.

Reitmann, F. (1938). Psychiat. Neurol. Wschr., 40, 391.

Simpson, T., and Barker, M. H. (1938). Arch. int. Med., 61, 208.

Stief, S. (1937). Psychiat. Neurol. Wschr., 39, 225.

\section{APPENDIX}

\section{Brief Case Histories of the Patients treated}

CASE E., aged 18.

This patient was admitted 3 months previous to commencing anoxia treatment, complaining of multiple obsessions of 8 months' duration. Family history revealed no abnormalities. His previous health had been good, without any mental or physical illnesses. He had been a moderate scholar, and taken six different posts since leaving school. He had always been shy and seclusive, with a tendency to obsessional traits and was always easily scared. He had always been described as slow and lazy, without special interests. The present illness began as a marked exacerbation of his previous obsessional trends, together with several rather bizarre new obsessions. These included a feeling that he had shot some people in a car, when an explosion occurred, that he should push people into the river as he crossed bridges, a fear that he had swallowed needles, ash-trays, tables, chairs, a bus, and even the eyes of people. As well as these multiple obsessions he has felt people talk about him and stare at him for the same length of time. On admission his behaviour was grossly interfered with 
by his obsessions, but was otherwise normal. There was no evidence of delusions or hallucinations ; his intelligence quotient was 84 . He had insight into the abnormality of his obsessions. There was no abnormality on physical examination. The condition was diagnosed as schizophrenia because of the bizarre nature and multiplicity of the obsessions. During his stay in hospital until the completion of anoxia treatment his condition remained essentially unaltered.

\section{CASE T., aged 16.}

This patient was admitted 1 month before commencing anoxia treatment, complaining of multiple obsessional symptoms. The family history revealed no abnormality. There were no significant mental or physical previous illnesses. He was an average scholar, but had eight different positions since commencing work at the age of 14. His personality was described as being quiet, shy, and readily irritated. He had few interests and only one friend. Though normally tidy, there were no previous obsessional traits. Six months previous to admission there was a gradual onset of obsessional washing. Three months later there was a sudden increase in his symptoms. New obsessions included the compulsion to put everything straight, eating from dishes which were placed on several inches of newspaper, a feeling that his nose was blocked while he was eating. The ritual of tidying his bed occupied several hours. On admission there were no abnormalities of behaviour, apart from those due to his obsessions. He was depressed and anxious over his condition, but there were no other psychiatric abnormalities. Physical examination was negative.

\section{CASE W., aged 25.}

This patient was admitted 6 weeks before commencing anoxia treatment, complaining of severe depression with bizarre depersonalization symptoms and ideas of reference. The illness had developed suddenly without discoverable precipitating cause. There were no abnormalities in the family history. His previous history revealed no significant mental or physical illnesses. He was evidently of average intelligence, having done fairly well at school, but had subsequently changed his work rather frequently. His previous personality had been shy, seclusive, and sensitive, with a general tendency to gloominess, but there were no mood swings. On admission he was normally orientated, but lay in bed listlessly and required tube feeding though was otherwise co-operative. At times there were repetitive movements of his hands suggesting stereotypy. His mood was one of profound self-accusatory depression associated with delusions of unworthiness. His attention was very poor and precise examination of his mental content was consequently difficult. He stated that his body was changed and that he no longer micturated nor defæcated. During his stay in hospital he became increasingly abstracted. At first he denied hallucinations, but later described a voice emanating from his left chest that gave orders to him. He recognized that he was ill, but showed no further insight. On physical examination there were no signs of disease, but his build was asthenic and poorly developed. There was a recent loss of $1 \frac{1}{2}$ stone in weight. His condition was diagnosed as schizophrenia.

\section{CAse A., aged 32.}

This patient was admitted 1 month before commencing treatment complaining of obsessional thinking, ideas of reference, and of influence associated with sexual preoccupations. His mother had suffered from a depressive psychosis, but there were no other relevant abnormalities in the family. His previous history revealed no significant mental or physical illnesses. His schooling had been normal and subsequently worked continuously as a clerk till this illness. His personality had, ever since 
childhood, been shy, reserved, and quiet. He had very few friends, but had no obsessional traits. For some years he had been worried over masturbation, and had become self-conscious, feeling that others could see the effects of masturbation in his face. For the last 6 months he had avoided all company, as he felt others could read his mind and also put thoughts into his head. During this period a great variety of obscene thoughts spontaneously entered his head, and at times his mind would go suddenly blank. On admission he was normally orientated and co-operative, but anxious and preoccupied with masturbation and his thought disorder. There were no other delusions or hallucinations. He attributes his present symptoms to masturbation. There was no physical abnormality on examination. The diagnosis was considered to be schizophrenia, and the thought disorder more characteristic of this condition than of an obsessional neurosis. 